\title{
Congenital orbital-intracranial teratoma with subsequent malignancy: case report
}

\author{
JOHN W GARDEN' ${ }^{1}$ AND JAMES C MCMANIS ${ }^{2}$ \\ From the 'Department of Ophthalmology, University of Kentucky Medical Center, and the ${ }^{2}$ Pathology \\ Laboratory, Central Baptist Hospital, Lexington, Kentucky, USA
}

SUMMARY A newborn baby had an orbital-intracranial benign teratoma radically excised with preservation of the eye. Three years later she developed recurrent proptosis, and reoperation showed an invasive orbital tumour that histologically was a malignant germ-cell neoplasm. The relationship of the two tumours is discussed. Malignant change in a benign orbital-intracranial teratoma of the newborn has not been previously reported.

The following report, that of an infant girl who underwent excision of an orbital-intracranial teratoma with recurrence as a malignant tumour at age 3 years is of interest.

\section{Case report}

The patient was seen at age 2 days for a proptosis of the right eye. On examination she failed to fixate a hand light with either eye, and there was no opticokinetic response. Exophthalmometry readings were $15 \mathrm{~mm}$ right and $10 \mathrm{~mm}$ left (Luedde). Extraocular motility was full. Palpably the eyes were symmetrically firm and could not be ballotted. No bruits could be heard. Funduscopic examination revealed a normal sized vasculature, sharp discs, and scattered blot haemorrhages in both eyes. The results of laboratory tests for routine haematological and biochemical values were within normal limits. A CT scan showed a large, inhomogeneous mass in the right orbit extending into the nasopharynx, the maxillary sinus, and the anterior cranial fossa.

Surgically the tumour was approached via a bifrontal craniotomy, orbitotomy, and lateral rhinotomy, with apparent total removal. Pathologically the orbital tumour was a $2 \times 1.25 \mathrm{~cm}$ cystic nodule which microscopically had smooth muscle forming the wall and a lining of columnar epithelium (Fig. 1A). The anterior fossa portion of the tumour was a $4 \mathrm{~cm}$ mass with neuroglial and fibrofatty tissue (Fig. 1B). A $2.5 \mathrm{~cm}$ cystic nodule lines by squamous epithelium with skin appendages and cartilage in the

Correspondence to James C McManis, MD, Pathology Laboratory Central Baptist Hospital, Lexington, Kentucky 40503, USA. wall formed the nasal portion (Fig. 1C). All three germinal layers were represented and no malignant elements were identified. Four months after surgery the patient followed lights and objects equally well, the corneal light reflexes were symmetrical, and her exophthalmometry reading was $14 \mathrm{~mm}$ in both eyes (Hertel). Both pupillary reactions were brisk, and the fundus haemorrhages had cleared.

The patient was well until age 3 , when she was noted to have swollen lids and chemosis on the right. Subsequently she did not fixate objects with the right eye, the right eye became proptotic, and a right Marcus Gunn pupil was noted. Exophthalmometry readings were $26 \mathrm{~mm}$ right eye and $14 \mathrm{~mm}$ left eye (Hertel). The right eye was displaced inferonasally,

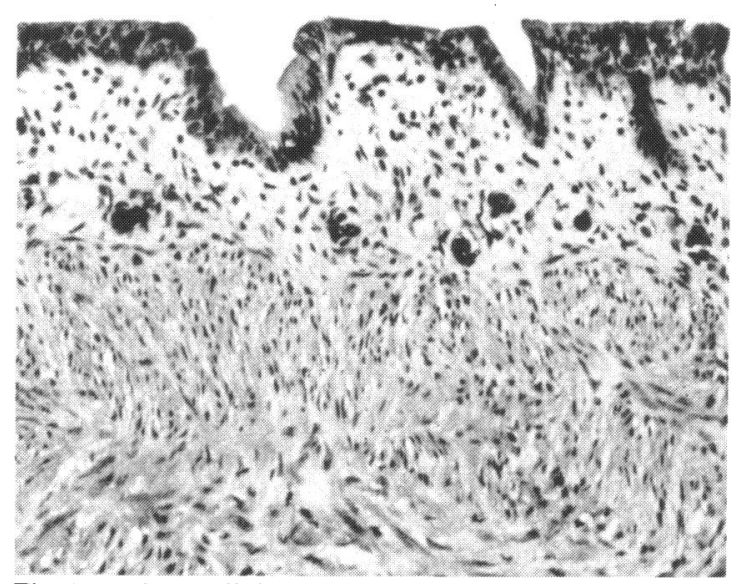

Fig. 1A Cyst wall showing smooth muscle and lining of columnar epithelium. (Haematoxylin and eosin, $\times 100)$. 


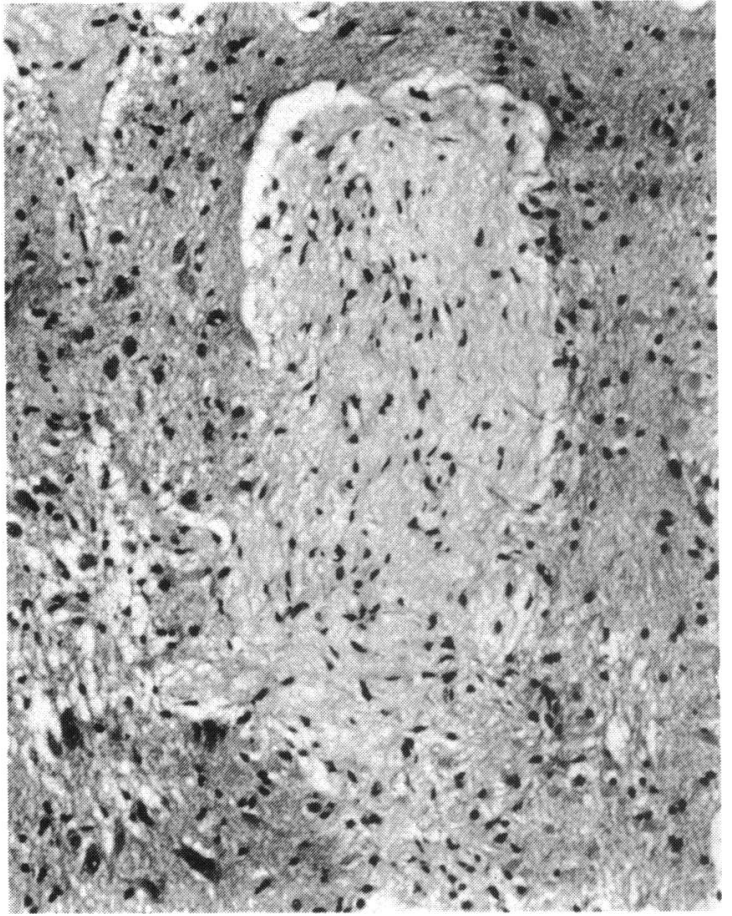

Fig. 1B Portion of tumour with glial tissue and neurons. (Haematoxylin and eosin, $\times 100$ ). with a limited motility. The right disc was hyperaemic, with a blurred margin, and a bruit could be heard over the right eye. The clinical impression was of a haemorrhage into a teratomatous cyst or rupture of the cyst. A CT scan showed an enhancing right orbital mass consistent with the above diagnosis. Again routine laboratory evaluation was unremarkable. A right frontal cranio-orbitotomy showed an infiltrative tumour in the muscle cone and optic canal. Biopsies and frozen sections revelead a malignant tumour. No attempt was made to resect it. Permanent sections showed a primitive epithelial tumour (Fig. 2). The final diagnosis was a malignant germ cell tumour. Tests for serum $\alpha$-fetoprotein and chorionic gonadotrophin were negative. Over the subsequent 18 months she received interval therapy every three weeks consisting of vinblastine, bleomycin, and cis platinun alternating with cyclophosphamide, actinomycin $\mathrm{D}$, and adriamycin. Radiation therapy totalled 4788 rads. Her last ophthalmological visit revealed questionable light perception on the right with a Marcus Gunn pupil but no evidence of recurrence of the tumour.

\section{Discussion}

This case represents two unusual aspects of congenital orbital-intracranial teratomas. First, the initial tumour was removed, with preservation of the eye and visual function. These tumours, although
Fig. 1C Acystic arealined by squamous epithelium with skin appendages. (Haematoxylin and eosin, $\times 100)$. 


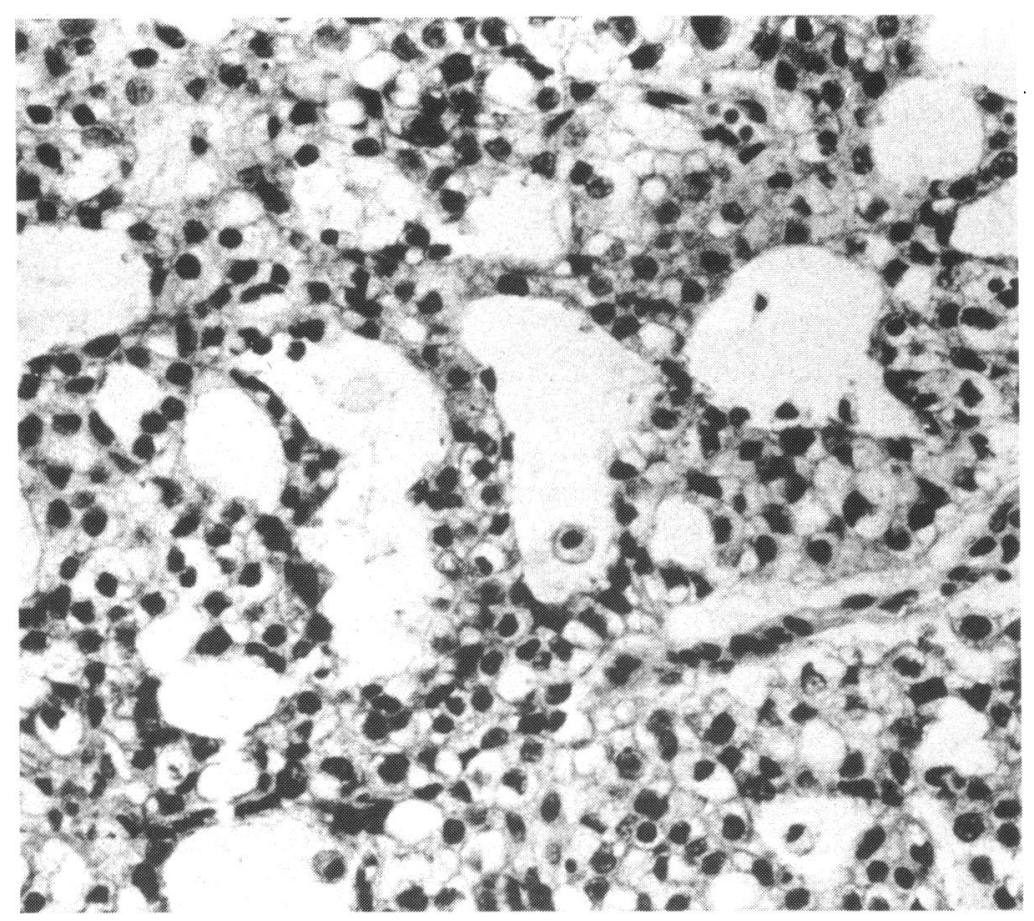

Fig. 2 Representative area of the primitive epithelial malignancy showing cystic or gland-like spaces. (Haematoxylin and eosin, $\times 400$ ).

considered benign, had previously been treated by exenteration. The change in surgical philosophy represented by this case has been discussed. 'Secondly, a malignant tumour appeared in an area where a congenital teratoma had been considered to be completely excised.

Congenital teratomas confined to the orbit and congenital intracranial teratomas are both uncommon. Fifty-two congenital intraorbital teratomas had been reported up to 1980 . $^{\prime}$ By definition an orbital teratoma does not extend beyond the confines of the orbit nor is it associated with teratomatous elements elsewhere in the cranium. The most complete review of reported intracranial teratomas of the newborn listed 24 and added another. ${ }^{2}$ One of these infants had a teratoma of both the middle fossa and orbit. $^{3}$

Teratomas are benign growths of mature and immature tissues which include derivatives of two or all three of the germ cell layers. ${ }^{4}$ Embryologically immature tissue in these tumours does not necessarily indicate malignancy. Malignant seminoma-like germ cell tumours are excluded from this discussion. True malignancy, as shown by the histological features of a carcinoma or sarcoma, has not been reported in intracranial teratomas of the newborn, ${ }^{2}$ though such cases in children or adults have been noted. ${ }^{5}$ A single case of 'malignant teratoma' of the orbit is not sufficiently documented in the report to be accepted. ${ }^{6}$
Unanswered questions remain. Was this a malignant germ cell tumour that arose de novo or malignant degeneration in an incompletely excised teratoma? Teratomas in other locations are known to undergo malignant change, and the latter possibility seems most likely in this case. Since congenital orbital teratomas are usually excised, and intracranial teratomas are either excised or a cause of death in the newborn, the chance for malignant transformation is lessened. As a result of this, as well as their rarity, the true malignant potential of these tumours cannot be determined. This case demonstrates the long-term potential for malignancy in these teratomas, despite apparent curative resection, and the need for caution in expressing the prognosis.

\section{References}

1 Chang DF, Dallow RL, Walton DS. Congenital orbital teratoma: report of a case with visual preservation. J Pediatr Opthalmol Strabismus 1980; 17: 88-95.

2 Greenhouse AH, Neubuerger KT. Intracranial teratoma of the newborn. Arch Neurol 1960; 3: 718-23.

3 Immisch V. Ein intrakranielles Teratom bei weiblicher Totgeburt. Zentralbl Allg Pathol 1952; 89: 163-6.

4 Willis RA. Pathology of tumours. London: Butterworth, 1967.

5 Tekeuchi J, Mori K, Moritake K, Tani F, Waga S, Handah H. Teratomas in the suprasellar region: report of five cases. Surg Neurol 1975; 3: 247-55.

6 Saradarian AV. Malignant teratoma of the orbit: six and one half years observation. Arch Ophthalmol 1947; 37: 253.

Accepted for publication 20 June 1985. 